\title{
BRAND CRISIS IN SOCIAL MEDIA: CASE STUDY USING SENTIMENT ANALYSIS
}

\section{DOI: 10.17261/Pressacademia.2018.968}

JMML- V.5-ISS.3-2018(9)-p.246-254

\author{
Abdullah Onden ${ }^{1}$, Meltem Kiygi-Calli ${ }^{2}$, Elif Yolbulan-Okan ${ }^{3}$ \\ ${ }^{1}$ Fabrikod, 34664, Üsküdar, Istanbul, Turkey. \\ abdullah.onden@fabrikod.com, ORCID: 0000-0003-3769-8193 \\ ${ }^{2}$ Kadir Has University, 34083, Fatih, Istanbul, Turkey. \\ meltem.kiygicalli@khas.edu.tr, ORCID: 0000-0002-2979-9309 \\ ${ }^{3}$ Bahçeşehir University, 34349, Beşiktaş, Istanbul, Turkey. \\ elif.okan@eas.bau.edu.tr, ORCID: 0000-0002-4691-7178
}

Date Received: July 25, 2018

Date Accepted: September 27, 2018

To cite this document

Onden, A., Kiygi-Calli, M., Yolbulan-Okan, E. (2018). Brand crisis in social media: case study using sentiment analysis. Journal of Management, Marketing and Logistics (JMML), V.5(3), p.246-254.

Permemant link to this document: http://doi.org/10.17261/Pressacademia.2018.968

Copyright: Published by PressAcademia and limited licenced re-use rights only.

\section{ABSTRACT}

Purpose- It is necessary to develop different crisis management strategies in order to understand their own images on consumers and to change the negative attitudes and perceptions to the positive ones. In this study, social media users' attitudes towards two different brands during the crisis were examined. The main purpose of this study is to give suggestions regarding the communication strategies that brands will develop through social media.

Methodology- Based on the text mining method, sentiment analysis was performed with Google Natural Language Processing on the data obtained from the Twitter which is a social media platform.

Findings- According to the results of the sentiment analysis conducted for two different brands, it is seen that social media users express a positive attitude to one of the firms, while they express a negative attitude to the other one.

Conclusion- In this study, the reasons of different attitudes of social media users were discussed. The reasons for this difference are thought to be because of the different sectors the companies belong to, different product category and their pricing strategy.

Keywords: Sentiment analysis, text mining, social media, Twitter, crisis management.

JEL Codes: M31, M39

\section{SOSYAL MEDYA'DA MARKA KRIZLERI: DUYGU ANALIZI YÖNTEMI ILE VAKA INCELEMESi}

\section{ÖZET}

Amaç- Farklı konularda kriz yaşayan markaların tüketici gözündeki kendi imajlarını takip etmeleri ve varsa negatif tutum ve algıların olumlu yönde değişmesi için farklı kriz yönetimi stratejileri geliştirmeleri gerekmektedir. Bu çalışmada kriz yaşanan iki farklı marka ile ilgili sosyal medya kullanıcılarının paylaşımları incelenerek bahsi geçen iki markaya karşı tutumları incelenmiştir. Kriz ortamında markaların sosyal medya üzerinden geliştirecekleri iletişim stratejileri konusunda öngörüler oluşturmak bu çalışmanın ana amacını oluşturmaktadır.

Yöntem- Twitter sosyal medya platformundan elde edilen veriler üzerinde metin madenciliği yöntemi kullanılarak Google Doğal Dil İşleme ile duygu analizi yapılmıştır.

Bulgular- İki farklı marka için yapılan duygu analizi sonuçlarına göre sosyal medya kullanııılarının kriz yaşayan firmalardan bir tanesine pozitif tutum sergilerken, diğerine negatif bir tutum sergilediği görülmektedir.

Sonuç- Bu çalışmada bulgular değerlendirilirken kriz yaşayan markalara karşı sosyal medya kullanıcılarının farklı tutum sergilemesinin nedenleri tartışılmıştır. Bu farklııı̆ın nedenlerinin farklı sektör, ürün sınıfı ve fiyat stratejisi olduğu düşünülmektedir.

Anahtar Kelimeler: Duygu analizi, metin madenciliği, sosyal medya, Twitter, kriz yönetimi.

JEL Kodları: M31, M39 


\section{GíRiş}

İletişim teknolojilerinin günümüzdeki kadar gelişmediği dönemde krizlerin yayılması çok daha zorken yönetilmesi daha kolaydı. Internet teknolojilerinin yaygın kullanılmasıyla birlikte markanın müşterileriyle iletişimi kolaylaşmış müşterilerle markalar düşünce paylaşımı açısından yakınlaşmışlardır. Bu gelişmeler pazarlama iletişimi açısından fırsatları doğururken kriz yönetimi açısından önemli tehditler oluşturmaktadır. Kriz, örgütün yaşamını tehdit eden durum olarak tanımlanmaktadır (Can, 1994). Günümüzde yaşanan en küçük krizin bile sosyal medyaya yansımaları yüzünden markanın itibarını olumsuz yönde etkileyebilecek boyutlara ulaştığı gözlemlenmektedir. Tüketicilerin markalarla yaşadığı olumsuz deneyimler sosyal medyada hızla yayılabildiğinden firmalar kriz yönetimi konusunda proaktif (öncü) önlemler alması gerekmektedir (Kalaycı, 2017; Yeniçıktı, 2016). Bu nedenle işletmelerin sosyal medya krizlerine karşı güçlü kriz planları oluşturmaları gerekmektedir.

Bu çalışma tüketicilerin kriz yaşayan iki marka hakkında sosyal medya aracılığı ile yaptığı yorumlar incelenerek hazırlanmıştır. Kriz dönemi esnasında firma ile ilgili Twitter üzerinden yapılan paylaşımlar metin madenciliği metodu ile analiz edilmiştir. bir veri tabanına kaydedilerek, her bir tweet duygu analizi ile yorumlanarak metnin pozitif, negatif veya nötr olarak tespit edilip sınıflandırıması sağlanmıştır. Bu çalışmanın amacı, krizin en sıcak olduğu dönemde sosyal medya kullanıcılarının algısını Twitter paylaşımları üzerinden yapılan duygu analizi yöntemiyle ölçmektir.

\section{LITERATÜR INCELEMESi}

Sosyal medya, kullanıcıların birbirleri ile bilgi alışverişi yapabildiği, dilediği içeriği oluşturup yönetebildiği özgür bir platformlardır (Kaplan ve Haenlein, 2010). Bu yeni medya akımında, diğer medya ortamlarından farklı olarak içeriği üretenler sadece profesyoneller değildir, internet kullanıcıları da içerik üretmektedirler. Bu akım, medyanın tek yönlü iletişimini çift yönlü diyalog hale getirmiştir (Solis ve Breakenridge, 2009). Sosyal medyanın yaygın kullanımı ile kullanıcılar beğendikleri ya da müşterileri oldukları markalarla iletişim kurma açısından daha da yakınlaşmışlar ve kendi düşünce, istek ve şikayetlerini doğrudan işletmelere iletebilir hale gelmişlerdir. Bu durum işletmeleri sosyal medya hesabı açması için teşvik etmekte ve burada aktif olmaya yönlendirmektedir. Böylece sosyal medyada aktif olan işletmeler sosyal medya kullanıcılarına iletmek istedikleri mesajları kolayca ulaştırma imkanı bulmaktadırlar. Bu kolaylık sosyal medya kullanıcılarının kendi aralarındaki iletişim açısından da ele alındığında, bir bilginin sosyal medyada yayılması artık dakikalarla ölçülmektedir. Burada bahsedilen iletişim olumlu bir mesaj olabileceği gibi olumsuz da olabilmektedir.

Illetişim teknolojilerinin hızla gelişmesi pazarlama ve marka yönetimi açısından fırsatlar sunmakla birlikte olası krizlerin çok hızlı yayılması tehlikesini de getirmektedir. Krizler, daha önce karşılaşılmayan, çoğu insan tarafından neden olunan, hatalı kararlar (Janis, 1989), teknolojik karmaşıklıklar (Perrow, 1984) ya da her ikisi (Pauchant \& Mitroff, 1992) aracılığıyla ortaya çıkmaktadır (Mishra, 1996). Tağraf ve Arslan (2003) krizi önceden beklenilmeyen ve sezilmeyen, örgüt tarafından çabuk ve acele cevap verilmesi gereken, örgütün önleme ve uyum mekanizmalarını yetersiz hale getirerek, mevcut değerlerini, amaçlarını ve varsayımlarını tehdit eden gerilim durumu olarak tanımlamıştır. Krizler işletmenin itibar kaybına yol açmaktadır.

Kriz yaşayan işletmeler önemli finansal, sosyal ve etik zorluklarla karşı karşıya kalmaktadırlar (Guth, 1995). Krizlerin ani olarak ortaya çıktığı düşünülse de krizler diğer kaynaklara bağlı olarak oluşuyorsa önceden bazı sinyaller verir. Kriz oluşumunda dört aşama bulunmaktadır. Bunlar; körlük, atalet, yanlış karar ve faaliyetler ve son olarak da krizin ortaya çıkmasıdır (Yeniçeri, 1993; Can,1994; Dinçer, 1992). Örneğin bir marka ile ilgili paylaşılan olumsuz bir içerik dakikalar içerisinde sosyal medyada yayılabilmekte ve bu da markalar açısından olumsuz bir imaj yaratabilmektedir. İşletmeler kriz yönetim sürecinde proaktif veya reaktif olarak iki farklı yaklaşımla kriz yönetimi yapabilirler. Proaktif kriz yönetimi, krizi önceden öngörüp onu engelleme ve krizi çözme yaklaşımıdır. Diğer taraftan reaktif kriz yönetimi ise kriz hasarını önleme ve varsa olan hasarları telafi etme veya iyileştirme yaklaşımıdır (Akdağ, 2005). Bu yüzden proaktif kriz yönetimi için işletmelerde kriz ekipleri kurulmaktadır (Sezgin, 2003). Böylece krizlere karşı hazırlıklı olunup krizlerin başarıyla atlatılması sağlanabilmektedir (Peker ve Aytürk, 2000).

Rekabetin çok yüksek olduğu günümüzde krizlerin daha az hasarla üstesinden gelebilmek için işletmelerde krizleri fırsata dönüştürebilecek yöneticiler bulunması çok önemlidir (Kadıbeşegil, 2003). Tüketici ve hedef kullanıcıların bulunduğu sosyal medya ortamı, doğru analiz yöntemleri uygulandığı takdirde şirketler için bir bilgi madenine dönüşmektedir. Örneğin Twitter üzerinden yapılan paylaşımların en yüksek sayıya 2014 yılındaki Dünya Kupası turnuvası tarih aralığında gerçekleştiği görülmüştür. Bu turnuva süresince yapılan toplam paylaşım sayısı 672 milyona çıkmıştır (Dredge, 2014). Bu noktada, böylesine büyük verilerin analizi için kullanılacak başarılı yöntemlerin geliştirilebilmesi için öncelikle mevcut veri kaynağını algılayabilecek gerekli algoritmaların üretilmesi gerekmektedir.

Markaların Twitter paylaşımlarını analiz edebilmesi için metin içeriklerindeki tüketici duygularının ve bu duyguların yoğunluklarının matematiksel olarak yorumlanabilmesi gerekmektedir. Bunun için bu çalışmada metin madenciliği yöntemi kullanılmıştır. Metin madenciliği, belirli bir standart ile düzenlenmemiş metinlerden anlamlı bilgiler çıkarmayı hedefleyen bir teknolojik araştırma yöntemidir (He vd., 2013). Metin madenciliği metnin diline göre hareket eden bir teknoloji olan doğal dil işleme disiplinini doğurarak daha anlamlı sonuçlar elde edilmesini sağlamıştır. (Delibaş, 2008). 
Bilgisayar biliminin giderek daha çok ilgi gösterdiği makine öğrenmesi ile metinlerdeki duygu yoğunluğunu araştırma çalışmaları da giderek daha başarılı sonuçlar vermeye başlamıştır. Bu teknolojiyi pazarlama kuramları ile birleştirip pazardaki büyük verileri analiz ederek, kişi ya da kurumların sosyal medya üzerindeki durumunun tespiti üzerine katkıda bulunulacağı düşünülmektedir. Bu çalışmada ele alınan iki örnek Uber ve Samsung krizleridir. Akıllı telefon sistemi üzerinden araç çağırma hizmeti sunan ve dünyanın en büyük ulaşım şirketlerinden biri olmayı başaran Uber sık sık sosyal medyada eleştirilere maruz kalmıştır. Bu çalışmada son zamanlarda kriz yaşamış iki markanın sosyal medya yansımaları incelenecektir.

Krizler işletmelerin itibar kaybına, iş gücü kaybına, finansal değer kaybına, marka değeri erozyonuna sebep olmasının ötesinde tüm paydaşları ve hatta ülke ekonomilerini etkileyebilecek boyutlara ulaşabilmektedir (Kavoğlu, 2013). Kalaycı (2017) makalesinde Turkcell'in yaşadığı sponsorluk krizini incelemiş ve firmanın yaşadığı krizin sosyal medyaya yansımaları neticesinde karlılıkta büyük ölçüde gerileme ve müşteri kaybına sebep olduğu tespit edilmiştir.

Bu çalışmada kriz yaşayan iki farklı markaya karşı sosyal medya kullanıcılarının nasıl tepkiler verdiği araştırılmıştır. İlk olarak Uber'in yaşadığı bir kriz ele alınmıştır. Uber şoförünün Boston'da bir kadına tecavüzü ile sonuçlanan ve 26 Nisan 2017 tarihinde davasının görülmesi ile sosyal medyada gündem olan bu olaya sosyal medya üzerinden verilen tepkiler incelenmiştir (Geanous, 2017). İkinci olarak ise Samsung'un batarya patlama krizi incelenmiştir. 2016 yılında Southwest Airlines'ın Lousville'den Baltimore'a gerçekleştirmiş olduğu 994 numaralı uçuşunda Samsung Galaxy Note 7'nin batarya patlaması sebebiyle Samsung satışa başladığı tarihten çok kısa bir süre sonra satışlarını durdurma kararı almıştır (Green, 2016). Bu çalışmada Uber ve Samsung markalarının yaşadığı krizler ile ilgili kullanıcıların sosyal medya paylaşımlarının duygu analizi yapılarak kişilerin bu olaylara karşı tutumları incelenmiştir.

\section{VERI VE METODOLOJI}

\subsection{Metodoloji}

Sosyal medyadaki büyük verinin analiz edilmesi için özellikle veri madenciliği metodu kullanılmaktadır. Veri madenciliği en kısa tanımı ile büyük ölçekli bir veri grubu arasından anlamı olan bilgiyi elde etme çalışmasıdır (Özkan, 2008). Diğer bir ifade ile veri madenciliği; veri tabanlarında depolanmış verilerden yeni, yararlı ve anlamlı bilgilerin edinilmesi işlemidir. Veri Madenciliği yöntemleri temel aldıkları teknik ve disiplinlere göre sınıflandırma, kümeleme ve birliktelik kuralları olarak gruplanabilir. Hangi sınıfa ait olduğu bilinmeyen kayıtların sınıf belirleme sürecine sınıflandırma, dağınık yapıdaki bir veri setini tanımlayıp düzene sokmak için belirli sayıda kümeye bölüp sıralama işlemine kümeleme adı verilir (Alpaydın, 2000).

Dağınık olan verileri belirli çerçevelerde toparlayıp analiz etmek pek çok değerli ilişkinin yakalanmasını sağlayabilir, bu ihtiyaçla metin madenciliği kavramı ortaya çıkmıştır (Özyurt, 2006). Metin Madenciliğinin çalışmaları ile örneğin, müşteri talep, şikayet, memnuniyet formları gibi yoğun şekilde gelen ve kontrolü güç metinlerin arşivlenip gruplanması ve bilgi çıkarımı ile gelen anlamlı bilgiler, ürün geliştirme, hata takip, işletme ile ilgili taleplerin değerlendirilmesi konularında işletmeye fayda oluşturur (Delen, 2008). Makine öğrenmesi, bilgisayarların veriye dayalı öğrenimini sağlayan algoritmaların tasarlanması ve geliştirilmesi süreçlerini konu alan yöntemdir. Makine öğrenmesi araştırmalarının odaklandığı konu, bilgisayarlara karmaşık yapıları algılama ve veriye dayalı akılı kararlar verebilme becerisi kazandırmaktır (Çiçekli, 1999). Makine öğrenmesinde hazırlık önemlidir. Çalışmaya başlamadan önce öğrenme yapılacak verilerin uygun bir şekilde hazırlanması gerekir. Öğrenme metodunda istatistiksel yöntemler kullanılır ve yeni metotlar da istatistik bilimine göre belirlenir. Yeni bir metod bulunduktan sonra bu metodun performansı ölçülür ve diğer metotlarla karşılaştırılması yapılır (Öztemel, 2006).

Bir cümlenin anlam içeriğinin analizi, cümle ile ifade edilmek istenilen duygu veya düşüncenin ne olduğunun anlaşılması işlemidir. Duygular, insanların nasıl davrandıkları ve farklı ilişkiler bağlamından nasıl ortaya çıktığıyla yakından ilgilidir. Anlamsal analiz yapılırken, öncelikli olarak kelimelerin tek tek veri tabanından uygun nesnelerle eşleştirilme işleminin yapılması gerekir (Esuli ve Sebastiani, 2010). Duygu analizi, doğal dil işlemenin giderek büyüyen bir alanıdır (Esuli ve Sebastiani, 2010) ve dil bilimleri ile duygusal yorumlama yapılmasını sağlamaktadır (Hatzivassiloglou ve McKeown, 1997). Özellikle sosyal medya üzerinden oluşan etkileşimlerin derecelendirilmesi ve bunun duygu analizi ile birleştirilmesi literatürde de son zamanlarda yapılan araştırmalar olarak karşımıza çıkmaktadır. Ibrahim vd. (2017)'de beş farklı markanın tüketici paylaşımlarının içeriklerini alıp duygu analizi yöntemi ile inceleyerek bu kişilerin markaya karşı tutumlarını araştırmıştır. Ayrıca özellikle Amazon'un Twitter üzerindeki çevrimiçi yardım masası ile Amazon müşterilerinin etkileşimleri araştırımış ve bunlar derecelendirilerek duygu analizi ile nasıl farklılaştığı incelenmiştir. Dünyada makine öğrenmesi, veri madenciliği ve doğal dil işleme üzerine en fazla yatırım yapan şirketlerden biri olan Google kullanıcılarının aramalarını anında analiz edip en doğru sonucu getirme noktasında sürekli çalışmalar yapıyor. 2016 yılının sonunda yayına aldığı "Cloud Natural Language" servisi ile birlikte doğal dil işleme ile ilgili ar-ge faaliyetlerini dünya kullanımına da sunmuş oldu (Google CNL, 2018).

Google Cloud Natural Language, karmaşık olmayan API servisi ile güçlü makine öğrenimi modelleri sunarak, metnin yapısını ve anlamını ortaya çıkararak metin belgeleri, haber makaleleri veya blog yazılarında belirtilen kişiler, yerler, etkinlikler ve daha fazlası hakkında bilgi almak için kullanılabilmektedir. 
İşletmeler ürünleri ile ilgili tüketicilerin duygu ve düşüncelerini sosyal medya platformları, internet blogları ya da mesajlaşma uygulamalarında kayıt edilen verileri doğru şekilde analiz ederek öğrenebilirler. Dokuz dile kadar destek veren Google Doğal Dil İşleme servislerinde bu verilerin içeriklerine göre sınıflandırılması, sözdizimi analizi, metinde geçen varlıkların tespiti ve duygu analizi temel özellik olarak sunulmaktadır. Google verileri sonuçlandırırken genel metne, metnin içindeki her cümleye bir skor ve magnitude ismini verdiği ve duygunun seviyesini ölçen bir değer vermektedir. Bu değer ne kadar yüksek olursa metin o kadar güçlü duygularla yüklüdür, negatif ya da pozitif değerler için de aynı şekilde incelenir. Duygu analizi skorlarında ise sonuçlar -1 ile 1 arasındadır. Değer düştükçe metin negatifleşirken, değer yükseldikçe metin pozitifleşir. Bu araştırmada Google'ın Doğal Dil İşleme kütüphanesi kullanılarak verilen API vasıtası ile tweet içeriklerinin duygu yoğunlukları tespit edilmiştir. Gönderilen her bir metin karşılığında Google'ın Cloud Natural Language API servisinden "score" yani metnin duygu puanı, "magnitude" yani duygu gücü ve "language" yani gönderilen metnin dili ile ilgili bir dönüş alınarak analiz yapılmıştır. Google -1.0 ile $-0,25$ arasındaki sonuçları negatif, 0.25 ile 1.0 arasındaki değerleri pozitif, -0.25 ile 0.25 arasındaki değerleri de nötr olarak nitelendirmektedir (Google CNL, 2018).

- Negatif: -1 ile -0.25 arasındaki değere sahip metinler negatif kabul edilir.

- Nötr: -0.25 ve 0.25 arasında değere sahip metinler nötr kabul edilir.

- Pozitif: 0.25 değerinden yüksek metinler pozitif içerikli kabul edilir.

Çalışmanın araştırma tasarımı Şekil 1'de verilmektedir. Araştırma tasarımına göre öncelikli olarak verilerin elde edileceği sosyal medya ağı belirlenmiştir. Burada veri kaynağı olarak dünyada en popüler sosyal paylaşım ağlarından biri olan Twitter kullanılmıştır. Araştırmanın ikinci adımında araştırmanın ana konusu olan kriz yaşayan iki marka seçilerek krizin en yoğun yaşandığı tarih aralığı belirlenmiştir. Bu çalışma için geliştirilen Python yazılımı ile ilgili dönemlerde, seçilen markalarla ilgili atılmış tweetler elde edilmiş ve oluşturulan veri tabanına kayıt edilmiştir. Daha sonra geliştirilen bu yazılım ile elde edilen verilerin yukarıda anlatılan Google Doğal Dil İşleme servisleri ile duygu analizi yapılmıştır. Bu duygu analizi sonuçlarına göre kullanıcıların yaptıkları paylaşımlar duygu skoru kümelendirmesi ile pozitif, negatif veya nötr olarak gruplandırılmıştır. Bu duygu analizi sonuçları üzerinden ele alınan iki markanın yaşadığı krizlerin sosyal medya kullanıcılarının tutumları incelenmiştir.

Şekil 1: Araştırma Tasarımı

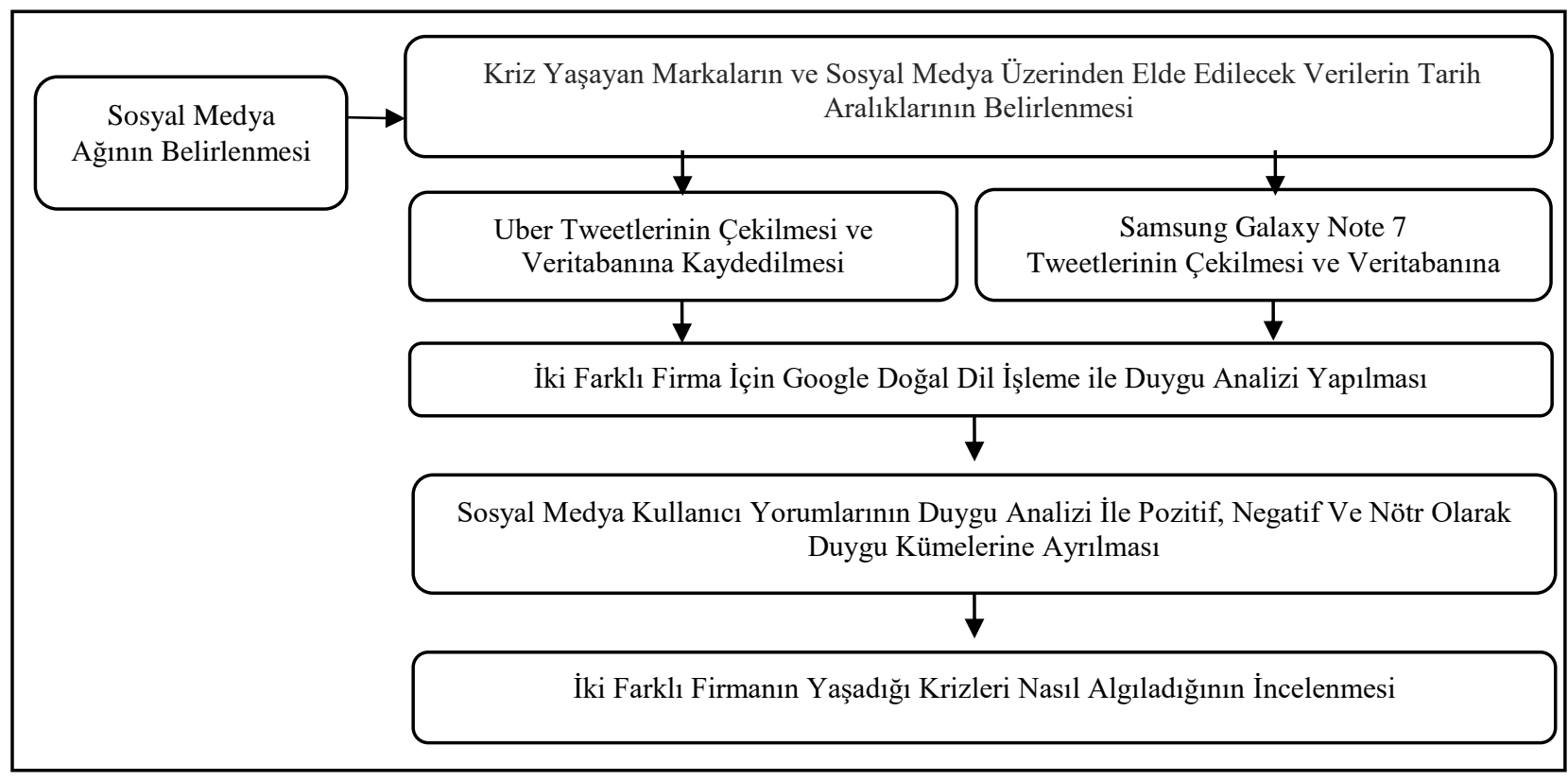

\subsection{Veri Seti}

Veri seti oluşturulması aşamasında, firmaların krizleri en yoğun yaşadıkları tarih aralığındaki tweetler çekilerek metin madenciliği tekniği ile bir veri tabanına kaydedilmiş, veriler düzenlendikten sonra Google Natural Language API vasıtası ile duygu analizi yapılarak, tweetlerin pozitif, negatif veya nötr oldukları tespit edilmiştir.

Uber ve Samsung' un yaşadığı krizler ve bu kriz döneminde Twitter kullanıcıları tarafından atılan tweetler üzerine çalışma yapılarak iki farklı markanın yaşadığı krizleri tüketicilerin nasıl algıladıkları incelenmiştir. Araştırmada ele alınan ilk firma olan Uber, 2009 yılında bir otomobil ve bir akıllı telefon sahibi herkesin taksicilik benzeri bir model ile gelir elde etmesini amaçlamış, insan taşıma 
gibi geleneksel bir konuyu yenilikçi bir yaklaşımla çözerken getirdiği uygun fiyat avantajı ve yenilikçilik ile milyar dolarlık bir güç haline gelmiştir. Bu süreçte sektördeki en büyük problem olan güvenlik hususunda çalışmalar yapmasına karşın güvenliği tehdit eden bazı olaylar yaşanmıştır.

Koreli teknoloji devi Samsung'un 2009 yılında Galaxy modeli ile akıllı telefon piyasasına girmesi ile birlikte rekabet iyice kızışmış ve bu sektör çok daha hızlı büyümeye başlamıştır. Her sene yeni birkaç Galaxy modeli üreten firmanın bilhassa Note serisi tüketiciler tarafından oldukça ilgi görmekte ve markanın akıllı telefonlarında amiral gemisi görevi görmektedir. Fakat 19 Ağustos 2016 tarihinde tanıtımı yapılan Galaxy Note 7 ürünü satış sonrası geri çağrılarak bataryaları değiştirilmiş, yenilenen bataryalarda da alev alma olayları yaşandığı için 11 Ekim 2016 tarihinde modelin üretimi tamamen durdurulmuştur. Bu olaylar sonucunda 2016 üçüncü çeyreğinde Samsung'un işletme karının \%30 oranında düştüğü görülmüştür (Burgess, 2016).

Bu çalışmada Uber ile ilgili 26-27 Nisan 2017 tarihleri arasında atılan 2362 tweet analiz edilmiştir. Samsung ile ilgili olarak 9-11 Eylül 2016 tarihleri arasında "\#galaxynote7" etiketi ile atılan 6592 tweet için duygu analizi yapılmıştır.

\section{BULGULAR VE TARTIŞMA}

Uber anahtar kelimesi ile çekilen 2361 tweet analize sokulduğunda atılan tweetlerin 1713'ünün İngilizce, 293'ünün İspanyolca, 14'ünün Japonca, 340'ının ise diğer dillerde olduğu tespit edilmiştir. Duygu analizi yapıldığında ise 1186 tweetin nötr, 395 tweetin negatif, 440'ının pozitif içerik içerdiği sonucuna ulaşılmıştır. Nötr tweetlerin duygu gücü değerlerine baktığımızda 0,00-0,20 aralığında yoğunlaşma görülmekte, bu da nötr ifadelerin genelde hafif ifadeler içerdiğini göstermekle birlikte az sayıda ağır ifadenin nötr olarak sonuçlandığı da görülmüştür. Duygu analizi yapılabilen 2021 tweetin \%58.7'sinin nötr, \%19'inin negatif, \%21,8'inin pozitif olduğu sonucuna ulaşılmıştır. Paylaşımların duygu analizi sonuçlarına bakıldığında belirtilen tarih aralığında yapılan Twitter paylaşımlarının ortalama duygu skoru 0,44 olarak bulunmuştur. Google pozitif duygu aralığı 0,25 ile 1,00 aralığında olduğu dikkate alındığında ortalama duygu skorunun $(0,44)$ pozitif duygu aralığında olduğu görülmektedir. Bu da gösteriyor ki belirtilen tarih aralığında sosyal medya kullanıcılarının \%19'unun negatif paylaşım yapmasına rağmen Uber markasına karşı kullanıcıların krize rağmen pozitif bir tutum sergiledikleri görülmektedir.

Tablo 1: Uber Markası İçin Yapılan Duygu Analizi Sonuçları

\begin{tabular}{|l|l|}
\hline Tarih Aralı̆̆ı & $26-27$ Nisan 2017 \\
\hline Analiz Edilen Toplam Tweet Sayısı & 2021 \\
\hline Pozitif Duygu İçeren Tweet Sayısı & 440 \\
\hline $\begin{array}{l}\text { Pozitif Duygu İçeren Tweetlerin Toplam Tweetler İçerisindeki } \\
\text { Payı }\end{array}$ & $\% 21,8$ \\
\hline Nötr Duygu İçeren Tweet SayıSı & 1186 \\
\hline $\begin{array}{l}\text { Nötr Duygu İçeren Tweetlerin Toplam Tweetler İçerisindeki } \\
\text { Payı }\end{array}$ & $\% 58,7$ \\
\hline Negatif Duygu İçeren Tweet Sayısı & 395 \\
\hline $\begin{array}{l}\text { Negatif Duygu İçeren Tweetlerin Toplam Tweetler İçerisindeki } \\
\text { Payı }\end{array}$ & $\% 19,5$ \\
\hline
\end{tabular}

Şekil 2'de Ingilizce olarak Twitter üzerinden paylaşılan bir tweet örneği bulunmaktadır. Burada paylaşımcı Uber hizmeti aldığında gelen araç modelinin Hummer olmasından çok memnun olduğunu dile getirmektedir. Şekil 3'te ise bu tweetin Google Doğal Dil İşleme'ye göre duygu analizi sonucu verilmektedir. Bu tweet'in duygu skoru 0.9 olarak hesaplanmıştır. Şekil 3'ün alt kısmında ayrıca verilen duygu skor tablosuna göre 0.9 duygu skoru pozitif duygu aralığında bulunmaktadır ve sonuç olarak duygu analizi sonucu pozitif olarak verilmektedir. 
Şekil 2: Pozitif Duygu iç̧eren Bir Tweet Örneği (Kaynak: Twitter.com)

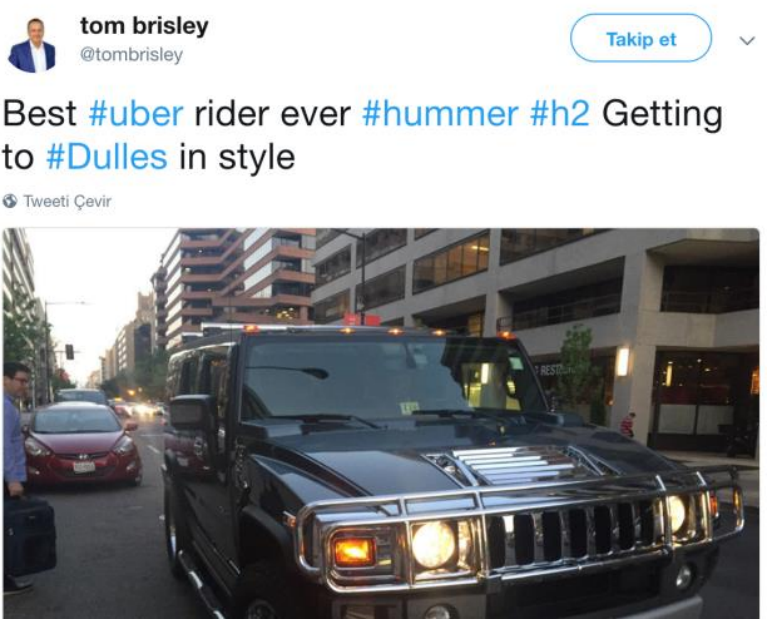

Şekil 3: Pozitif Bir Tweet'in Duygu Analizi Sonucu

Tüm Metnin Duygu Analizi

Best \#uber rider ever \#hummer \#h2 Getting to \#Dulles in style

Galaxynote7 etiketi ile çekilen 6591 tweetin 4022 adedinin İngilizce, 822'sinin İspanyolca, 103 adedinin Japonca, kalan 1644'ünün diğer dillerde olduğu görülmüştür. Google duygu analizi yalnızca İngilizce, İspanyolca ve Japonca dillerine destek vermektedir. Beta olarak Çince, Fransızca, Almanca, İtalyanca, Korece ve Portekizce destek verse de bunlar henüz resmen duyurulmadığı için bu çalışmada kullanılamamış ve kısıtlanmıştır, sonraki çalışmalarda bu dillerde de çalışma yapılabilir. Google'ın duygu analizi desteği verdiği dillerde yapılan çalışmada bu tweetlerin 3146 tanesinin nötr, 1076 tanesinin negatif, 725 tanesinin de pozitif olduğu bulunmuştur. Bu sonuçlara göre duygu analizi yapılabilen 4947 tweetin \%63,59'u nötr iken, \%21,75'i negatif, \%14,65'i pozitiftir. Şekil 2'de Samsung Galaxy No 7 ile ilgili paylaşılmış negatif içerikli bir tweet örneği incelenebilir. Paylaşımların duygu analizi sonuçlarına bakıldığında belirtilen tarih aralığında yapılan Twitter paylaşımlarının ortalama duygu skoru -0,04 olarak bulunmuştur. Google nötr duygu aralığı $-0,25$ ile 0,25 aralığında olduğu dikkate alındığında ortalama duygu skorunun $(-0,04)$ nötr duygu aralığında olduğu görülmektedir. Bu da gösteriyor ki belirtilen tarih aralığında sosyal medya kullanıcılarının \%21,75'inin negatif paylaşım yapmasına rağmen Samsung markasına karşı kullanıcıların krize rağmen nötr bir tutum sergiledikleri görülmektedir.

Tablo 2: Samsung Markası İçin Yapılan Duygu Analizi Sonuçları

\begin{tabular}{|l|l|}
\hline Tarih Aralığı & $9-11$ Eylül 2016 \\
\hline Analiz Edilen Toplam Tweet Sayısı & 4947 \\
\hline Pozitif Duygu İçeren Tweet Sayısı & 725 \\
\hline Pozitif Duygu İçeren Tweetlerin Toplam Tweetler İçerisindeki Payı & $\% 14,6$ \\
\hline Nötr Duygu İçeren Tweet Sayısı & 3146 \\
\hline Nötr Duygu İçeren Tweetlerin Toplam Tweetler İçerisindeki Payı & $\% 63,6$ \\
\hline Negatif Duygu İçeren Tweet Sayısı & 1076 \\
\hline Negatif Duygu İçeren Tweetlerin Toplam Tweetler İçerisindeki Payı & $\% 21,8$ \\
\hline
\end{tabular}

Şekil 4'te İngilizce olarak Twitter üzerinden paylaşılan içerikli bir tweet örneği bulunmaktadır. Burada kullanıcı Samsung Galaxy Note 7 telefonuyla ilgili negatif içerikli bir tweet atarak, Samsung telefonunun patlamadığı için şanslı olduğunu düşündüğünü belirtmiştir. Şekil 5'te bu tweetin Google Doğal Dil İşleme'ye göre duygu analizi sonucu verilmektedir. Bu tweet'in duygu skoru 0.8 olarak hesaplanmıştır. Kullanıı paylaşımında duygusal tepkilerini emojilerle açıklayarak ifadesini güçlendirmiştir. Google Doğal Dil İşleme sistemi emojileri de analiz içine sokarak daha doğru bir duygu analizi yapılmasını sağlamıştır. Şekil 5'in alt kısmında ayrıca verilen duygu skor tablosuna bakıldığında -0.8 duygu skoru negatif duygu aralığında bulunmaktadır ve sonuç olarak duygu analizi sonucu negatif olarak verilmektedir. 


\section{Şekil 4: Negatif Duygu İçeren Bir Tweet Örneği (Kaynak: Twitter.com)}

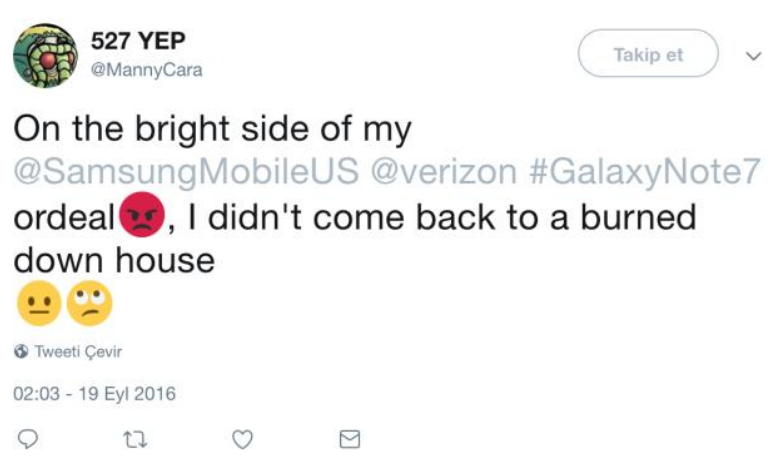

Şekil 5: Negatif Bir Tweet'in Duygu Analizi Sonucu

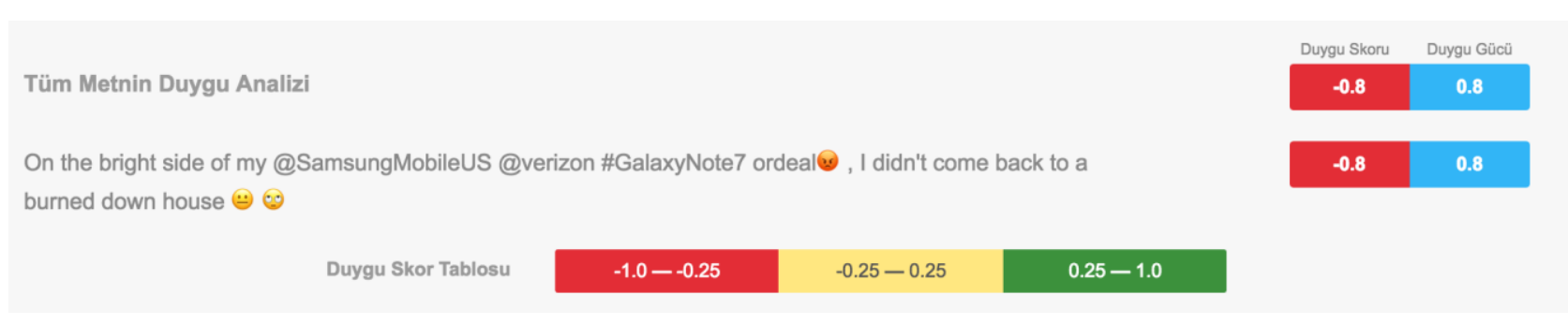

\section{SONUÇ}

Bu çalışmada kriz yaşayan iki markaya karşı sosyal medya kullanıcılarının tutumları örnek olaylar olarak incelenmiştir. Kriz yaşayan firmalardan dünyada geniş yer bulmuş Samsung ve Uber seçilmiştir. Araştırmaya konu olan markaların sosyal medya üzerinden kullanıcıların yapmış olduğu paylaşımlar özel bir yazılım ile elde edilmiş ve veri tabanı oluşturulmuştur. Daha sonra elde edilen verilerin Google Doğal Dil İşleme metodu ile duygu analizleri yapılmış ve kullanıcıların büyük krizler yaşayan bu markalara karşı tutumları pozitif, negatif veya nötr olarak değerlendirilmiştir. Elde edilen sonuçlara göre Uber markası ile ilgili yapılan paylaşımların ortalama duygu skoru 0,44 olarak bulunmuştur. Bu sonuç kullanıcı tutumlarının genel olarak pozitif yönde olduğunu göstermektedir. Samsung Galaxy Note 7 ürünü ile ilgili paylaşımlara bakıldığında ise sosyal medya kullanıcılarının bu ürünle ilgili tutumlarının ortalama duygu skorunun $-0,04$ olduğu görülmektedir. Bu sonuç bize bu marka ve özellikle Galaxy Note 7 ile ilgili yaşanan krize karşı tutumlarının Uber markası krizine göre çok daha negatif olduğunu göstermiştir. Bu sonuçlar tüketicilerin iki farklı markanın yaşadığı krizlerle ilgili algılarının farklı olduğu, Uber'e Samsung’a olduğundan daha pozitif yaklaştıkları şeklinde yorumlanabilir. Ayrıca iki krizin içerik anlamında farklılıkları bulunduğu göz önüne alınmalıdır. Örneğin Samsung'un yaşadığı krizin doğrudan insan sağlığını tehdit eden bir durum olması ve Uber'in hizmet sektöründe tüketiciye rahatlık sunan önemli bir avantaj sağlaması sonuçları yorumlarken dikkate alınmalıdır. Ayrıca aynı dönemde bu firmaların yaşadıkları kriz karşısında nasıl bir iletişım stratejisi benimsedikleri önemlidir. Bunun yanı sıra Uber ve Samsung firmalarının birbirinden oldukça farklı yapısı olması, tepkilerin farklı düzeyde olmasına neden olmuştur. Uber'in daha genç, yenilikçi ve paylaşımcı yapısı tüketicilerin işletmenin yaşadığı sorunlara daha anlayışlı bakmasını sağlamış olabilir.

Bu çalışmada da görüldüğü gibi firmalar sosyal medya kullanımlarını sadece tanıtım amaçlı değil kriz yönetimi odaklı kurgulamak zorundalar. Çünkü, zaman ve mekan kısıtı olmadan atılan tweetlerin fima adına yaratılan kalıcı bir dijital ayak izi yaratacağı düşüncesi ile firmalar krizleri önlemeyi ve bunun ötesinde fırsata çevirmeyi öğrenmelidirler (Arıcı, 2001). Sonuçlar ele alındığında nötr tweetlerin Google'ın duygu yoğunluğu puanlaması ile daha iyi yorumlanabilmesi mümkündür, genişletilmiş çalışmalarda bu parametre de yapılandırılarak araştırılabilir. Ayrıca Uber ve Samsung'un o dönemde yaptığı iletişim stratejileri ve sosyal medyadaki mesajları incelenerek kriz yönetimleri performansları da ileriki çalışmalarda değerlendirebilir. Markaların kriz anlarında sosyal medya üzerinden yapacakları çeşitli kampanyalar veya etkinlikler sayesinde kullanıcıların zihinlerinde oluşan negatif algıyı pozitife çevirmeye çalışmaları gerekmektedir. Ayrıca farklı ürün ve hizmetleri hakkında sosyal medyada içerik oluşturup paylaşımlar yapmaları marka farkındalığını da artıracaktır. İleriki çalışmalarda farklı sektörlerden farklı konuda yaşanan krizlerin incelenmesi ve markaların farklı iletişim stratejilerinin incelenerek tüketiciler üzerinde farkındalıklarını artırmaları da kriz yönetimi açısından firmalara önemli içgörü sağlayacaktır. 


\section{KAYNAKLAR}

Akdağ, M. (2005). Halkla ilişkiler ve kriz yönetimi. Selçuk Üniversitesi Sosyal Bilimler Enstitüsü Dergisi, (14), 1-20.

Alpaydın, E. (2000). Zeki veri madenciliği: ham veriden altin bilgiye ulaşma yöntemleri. Bilişim 2000 Eğitim Semineri, Boğaziçi Üniversitesi, İstanbul. Arıcı, K. (2001). Krizler firsata dönüştürülebilir. Türk-Koop Dergisi, 17, 345.

Burgess, M. (2016). Samsung blames drop in profits on Galaxy Note 7 problems. Erişim: https://www.wired.co.uk/article/samsung-profits-dropnote-7.

Can, H. (1994). Organizasyon ve yönetim. Siyasal Kitapevi, 3. Baskı, Ankara.

Çiçekli, İ. (1999). Tercüme kaliplarinin makina öğrenmesi teknikleri ile tercüme örneklerinden öğrenilmesi. TÜBiTAK Projesi, Proje No: EEEAG244(197E011).

Delen, D., Crossland, M.D. (2008). Seeding the survey and analysis of research literature with text mining. Expert Systems with Applications. 34, 1707-1720.

Delibaş, A. (2008). Doğal dil işleme ile Türkçe yazim hatalarinin denetlenmesi. Yüksek Lisans Tezi, İstanbul Teknik Üniversitesi Fen Bilimleri Enstitüsü, Bilgisayar Mühendisliği Ana Bilim Dalı, İstanbul, Türkiye, 1-5.

Dinçer, Ö. (1992). Stratejik yönetim ve işletme politikası. Timaş Yayınları, 2. Baskı, İstanbul.

Dredge, S. (2014). World Cup was biggest event yet for Twitter with 672m tweets. Erişim: https://www.theguardian.com/technology/2014/jul/15/twitter-world-cup-tweets-germany-brazil.

Esuli, A., Sebastiani, F. (2010). Machines that learn how to code open-ended survey data. International Journal of Market Research, 52(6), 775800.

Geanous, J. (2017). Boston Uber driver charged with rape. Erişim: https://www.bostonglobe.com/metro/2017/04/25/boston-uber-drivercharged-with-rape/fcddNesDx5m6iadF4H4kJK/story.html.

Google CLN. (2018). Cloud natural language web site. Erişim: https://cloud.google.com/natural-language.

Green, B. (2016). Replacement Samsung Galaxy Note 7 phone catches fire on Southwest plane. Erişim: https://www.theverge.com/2016/10/5/13175000/samsung-galaxy-note-7-fire-replacement-plane-battery-southwest.

Guth, D. W. (1995). Organizational crisis experience and public relations roles. Public Relations Review, 21(2), $123-136$.

Hatzivassiloglou, V., McKeown, K. R. (1997). Predicting the semantic orientation of adjectives. In Proceedings of the 35th annual meeting of the association for computational linguistics and eighth conference of the european chapter of the association for computational linguistics (pp. 174181). Association for Computational Linguistics.

He, W., Zha, S., Li, L. (2013). Social media competitive analysis and text mining: a case study in the pizza industry. International Journal of Information Management, 33(3), 464-472.

Ibrahim, N. F., Wang, X., Bourne, H. (2017). Exploring the effect of user engagement in online brand communities: evidence from Twitter. Computers in Human Behavior, 72, 321-338.

fJanis, I. L. (1989). Crucial decisions: leadership in policymaking and crisis management. New York: Free Press.

Kadıbeşegil S. (2003). Kriz geliyorum der, kriz iletişimi ve yönetimi. MediaCat, İstanbul.

Kalaycı, B. N. (2017). Sosyal medyada kriz iletişimi; Turkcel örneği. I. Uluslararası İletişimde Yeni Yönetilimler Konferansı (pp. 331-341).

Kaplan, A. M., Haenlein, M. (2010). Users of the world, unite! The challenges and opportunities of Social Media. Business Horizons, 53 (1), 59-68.

Kavoğlu, S. (2013). Güncel bir olgu olarak yeni medya ve kriz iletişimi: örnek vaka analizi. Gümüşhane Üniversitesi illetişim Fakültesi Elektronik Dergisi, 2(1), 49-63.

Mishra, A. K. (1996). Organizational responses to crisis. Trust in organizations: Frontiers of theory and research, 261.Pauchant, T. C. \&Mitroff, I. I. 1992. Transforming the crisis-prone organization: Preventing individual, organizational, and environmental tragedies. San Francisco, CA: JosseyBass.

Özkan, Y. (2008). Veri madenciliği yöntemleri. Papatya Yayıncılık, İstanbul.

Öztemel, E. (2006). Yapay sinir ağlari. Papatya Yayıncılık, İstanbul

Özyurt, Ö., Köse, C. (2006). Türkçe tabanli diyalog sistemi tasarimi ve internet (chat) ortamlarindan bilgi çikarimi. Karadeniz Teknik Üniversitesi.

Pauchant, T. C., Mitroff, I. I. (1992). Transforming the crisis-prone organization: preventing individual, organizational, and environmental tragedies. San Francisco, CA: Jossey-Bass.

Peker, Ö., Aytürk, N. (2000). Etkili yönetim becerileri. Yargı Yayınevi, Ankara 
Perrow, C. (1984). Normal accidents: living with high-risk technologies. New York: Basic Books.

Sezgin, F. (2003). Kriz yönetimi. Manas Sosyal Bilimler Dergisi, 4(8), 111-119.

Solis, B., Breakenridge, D. (2009). Putting the public back in public relations. New Jersey, FT Press, 180.

Tağraf, H., Arslan, N. T. (2003). Kriz oluşum süreci ve kriz yönetiminde proaktif yaklaşım. C.Ü. İktisadi ve İdari Bilimler Dergisi, 4(1), 149-160.

Yeniçeri, Ö. (1993). İşletmelerde yönetim, organizasyon ve davranış. Tutibay Basım A.Ş, Ankara. 